\title{
PRETREATMENT WITH LIDOCAINE FOR PREVENTING THE WITHDRAWAL MOVEMENTS ASSOCIATED WITH INTRAVENOUS INJECTION OF ROCURONIUM - A PROSPECTIVE, DOUBLE BLINDED, RANDOMISED AND PLACEBO CONTROL STUDY
}

\author{
Namrata Ranganath ${ }^{1}$, V. B. Gowda ${ }^{2}$ \\ ${ }^{1}$ Associate Professor, Department of Anaesthesiology and Pain Relief, Kidwai Memorial Institute of Oncology, Bangalore. \\ ${ }^{2}$ Associate Professor, Department of Anaesthesiology and Pain Relief, Kidwai Memorial Institute of Oncology, Bangalore.
}

\section{ABSTRACT}

\section{BACKGROUND}

Rocuronium has the fastest onset of action among the non-depolarising muscle relaxants. It is frequently used as an alternative to succinylcholine in situations in which rapid control of the airway is required and succinylcholine is contraindicated. It is observed that the intravenous injection of rocuronium after the induction of anaesthesia is often associated with a localised withdrawal of the arm or generalised movement; hence, this study was designed to find out that pain from injection of Rocuronium can be attenuated or abolished by previous administration of an intravenous local anaesthetic.

\section{MATERIALS AND METHODS}

Sixty patients $>18$ years of age, Sex - male or female, American Society of Anaesthesiologists Status I, II or III, undergoing general anaesthesia were randomly assigned by card-draw to one of two groups: Group I=placebo, Group II=lidocaine. Patients assigned to the lidocaine group received preservative - free $1 \%$ lidocaine $(1 \mathrm{mg} / \mathrm{kg}=0.1 \mathrm{~mL} / \mathrm{kg})$. Patients assigned to the placebo group received $0.1 \mathrm{~mL} / \mathrm{kg}$ of preservative-free isotonic sodium chloride solution. After the administration of oxygen, both groups of patients underwent the intravenous induction of anaesthesia using $2.5 \%$ sodium thiopental $5 \mathrm{mg} / \mathrm{kg}$ followed by free flow of IV fluid. Five seconds later, manual occlusion of the forearm was performed with sufficient force to stop the IV flow by gravity, and the study drug was injected over 10 seconds. Manual forearm pressure was maintained for $15 \mathrm{~s}$, and then released and a tracheal intubating dose of $0.6 \mathrm{mg} / \mathrm{kg}$ of rocuronium at room temperature is injected over 10-15 s. The patient's response to rocuronium injection was graded using a 4-point scale, proposed by Shevchenko and Colleagues. After the response was graded, the study was terminated and the anaesthetic continued at the discretion of an attending anaesthesiologist.

\section{RESULTS}

15 of 30 patients (50.0\%) in the placebo group had pain on injection of rocuronium and showed movement as compared to only 6 of 30 patients $(20.0 \%)$ in the Lidocaine group; none of the patients showed allergic reactions after injection of rocuronium or the pretreatment. No erythema or venous sequelae were observed in any patient during the 24-hour follow-up and none remembered any pain or discomfort at the time of induction of anaesthesia. No other complications attributable to the drugs were noted. No patient complained of any residual pain.

\section{CONCLUSION}

This study demonstrates that the IV injection of rocuronium after IV pentothal produces significant limb withdrawal or generalised movement in most adult patients. This reaction can be decreased in incidence and severity by the prior administration of $1 \%$ lidocaine, $1 \mathrm{mg} / \mathrm{kg}$ with the manual occlusion technique maintained for 15 seconds before the injection of rocuronium.

\section{KEYWORDS}

Rocuronium, Lignocaine, Withdrawal Movement, Occlusion Technique, Intubating Dose.

HOW TO CITE THIS ARTICLE: Ranganath N, Gowda VB. Pretreatment with lidocaine for preventing the withdrawal movements associated with intravenous injection of rocuronium - a prospective, double blinded, randomised and placebo control study. J. Evolution Med. Dent. Sci. 2016;5(89):6606-6610, DOI: 10.14260/jemds/2016/1494

\section{INTRODUCTION}

Rocuronium bromide (Org 9426) is an aminosteroidal neuromuscular blocking drug of rapid onset and intermediate duration of action. Rocuronium has the fastest onset of action among the non-depolarising muscle relaxants. It was developed out of a need for an agent with a rapid onset and

Financial or Other, Competing Interest: None.

Submission 18-08-2016, Peer Review 19-09-2016,

Acceptance 22-09-2016, Published 05-11-2016.

Corresponding Author:

Dr. Namrata Ranganath,

\#202, Shankari Apartment,

Ist Hamadu Cross,

Banashankari III Stage,

Bangalore-85.

E-mail: namrang@gmail.com

DOI: 10.14260/jemds/2016/1494 short duration of action, and a low risk of side effects. Rocuronium's onset of action is comparable to that of succinylcholine, but its duration of action is significantly longer. It is frequently used as an alternative to succinylcholine in situations in which rapid control of the airway is required and succinylcholine is contraindicated.

A variety of intravenous anaesthetic agents cause pain when injected. ${ }^{1}$ Pain on injection of rocuronium is common, occurring in $40 \%-94 \%$ of patients (Table 1 ) and lasts for approximately 10 to 20 seconds. $^{2}$ It is observed that the intravenous injection of rocuronium after the induction of anaesthesia is often associated with a localised withdrawal of the arm or generalised movement suggesting the presence of intense nociception, even during anaesthesia.3,4,5,6,7 Such movements have been reported to be secondary to discomfort or pain at the site of injection in conscious patients. ${ }^{8,9,10,11,12,13,14,15}$ 
Such spontaneous movements during induction can cause dislodgement of the intravenous catheter or rarely even pulmonary aspiration secondary to gastric regurgitation after generalised spontaneous movements during rocuronium injection. Pain from injection of Rocuronium can be attenuated or abolished by clinical treatments used for the prevention of pain on injection of propofol, such as previous administration of an intravenous local anaesthetic.

\section{METHODS}

After obtaining approval from Institutional Ethics Committee, the patients were selected from Pre-Anaesthetic Clinic of Kidwai Memorial Institute of Oncology, Bangalore.

The study is designed to be prospective, double blinded, randomised and placebo controlled.

Sixty patients $>18$ years of age, Sex-male or female, American Society of Anaesthesiologists Physical Status I, II or III, undergoing general anaesthesia were randomly assigned by card-draw to one of two groups: Group I=placebo, Group II=lidocaine, Patients with neurologic deficits, Patients with chronic pain syndromes, Parkinson's disease or weak, thin dorsal veins or allergies to thiopental, rocuronium or lidocaine was excluded. Patients who have received analgesics within the previous 24 hours were also excluded.

On arrival of the patient in the operating room, routine non-invasive monitors of Electrocardiogram, pulse oximeter, non-invasive blood pressure monitor were placed. An 18gauge intravenous catheter was placed on the dorsum of the hand. Free flow of lactated Ringer's IV fluid was confirmed by allowing the administration of $20 \mathrm{~mL}$ by gravity.

Identical syringes containing each drug at ambient temperature $\left(20-24^{\circ} \mathrm{C}\right)$ was prepared according to card draw. Patients and investigators who scored the movements were blinded to the treatment group and an independent researcher prepared the study solution. Patients assigned to the lidocaine group received preservative-free $1 \%$ lidocaine $(1 \mathrm{mg} / \mathrm{kg}=0.1$ $\mathrm{mL} / \mathrm{kg}$ ). Patients assigned to the placebo group received 0.1 $\mathrm{mL} / \mathrm{kg}$ of preservative-free isotonic sodium chloride solution.

After the administration of oxygen, both groups of patients underwent the intravenous induction of anaesthesia using $2.5 \%$ sodium thiopental $5 \mathrm{mg} / \mathrm{kg}$ followed by free flow of IV fluid. Five seconds later manual occlusion of the forearm was performed with sufficient force to stop the IV flow by gravity and the study drug was injected over 10 seconds. Manual forearm pressure was maintained for $15 \mathrm{~s}$, and then released and a tracheal intubating dose of $0.6 \mathrm{mg} / \mathrm{kg}$ of rocuronium at room temperature is injected over 10-15 s. All medications were injected into a port connected directly to the IV catheter, while the IV tubing was clamped above the injection site. Mask ventilation was initiated with oxygen, $\mathrm{FiO}_{2}$ of 1.0 , once the patient became unconscious and apnoeic.

The patient's response to rocuronium injection was graded using a 4-point scale, proposed by Shevchenko and Colleagues. ${ }^{6}$ After the response was graded the study was terminated and the anaesthetic continued at the discretion of an attending anaesthesiologist.
Local signs were immediately assessed in the arm receiving the injection and also at 1 and 24 hours after recovery from anaesthesia as follows:

Erythema=redness, thrombosis=hardness of the vein, phlebitis=tenderness on palpation of the vein, or thrombophlebitis=tender and hard vein. Thrombosis, phlebitis and thrombophlebitis were summarised as venous sequelae. Patients were asked $24 \mathrm{~h}$ after recovery from anaesthesia whether they had recall of pain or movements in this arm during induction of anaesthesia.

\section{DATA COLLECTION TECHNIQUES \\ Primary Data Collection}

(Dependent Study Variables)

After the study drug was injected, the patient's response was graded by the anaesthesiologist as proposed by Shevchenko and Colleagues in 1999.

1. No response,

2. Movement at the wrist only,

3. Movement/withdrawal involving arm only (Elbow/shoulder),

4. Generalised response-withdrawal or movement in more than one extremity, cough or breath-holding.

The patient's heart rate, mean arterial blood pressure is recorded before and 1 minute after injecting rocuronium.

\section{Data Analysis Plan}

Age and weight is compared between the groups by using an Independent samples t-test and is summarised as mean $\pm \mathrm{SD}$. Paired ' $\mathrm{t}$ ' test is used to compare sex distribution characteristics between the two groups. The mean of the haemodynamic variables is compared between the two groups using Independent samples t-test. The two groups were compared on response level using a rank test (Mann-Whitney U-test). Data is tabulated and presented graphically. Statistical significance is defined as $\mathrm{P}<0.05$.

\section{RESULTS}

60 patients were enrolled for the study; demographic characteristics such as age, weight and sex were comparable.

Response to Rocuronium Administration

\begin{tabular}{|c|c|c|c|c|}
\hline \multicolumn{2}{|c|}{} & \multicolumn{2}{|c|}{ Groups } & \multirow{2}{*}{ Total } \\
\cline { 3 - 4 } & Placebo & Lidocaine & \\
\hline \multirow{4}{*}{ Response** $^{\text {No Movement }}$} & 15 & 24 & 39 \\
\cline { 2 - 5 } & $\begin{array}{c}\text { Movement at } \\
\text { Wrist }\end{array}$ & 4 & 4 & 8 \\
\cline { 2 - 4 } & $\begin{array}{c}\text { Movement } \\
\text { Involving } \\
\text { Arm only }\end{array}$ & 9 & 2 & 11 \\
\cline { 2 - 4 } & $\begin{array}{c}\text { Generalised } \\
\text { Response* }\end{array}$ & 2 & 0 & 2 \\
\hline \multicolumn{2}{|c|}{ Total } & $\mathbf{3 0}$ & $\mathbf{3 0}$ & $\mathbf{6 0}$ \\
\hline \multicolumn{2}{|c|}{ Table 1: Response Grading } \\
\hline
\end{tabular}

15 of 30 patients $(50.0 \%)$ in the placebo group had pain on injection of rocuronium as compared to only 6 of 30 patients $(20.0 \%)$ in the lidocaine group. 


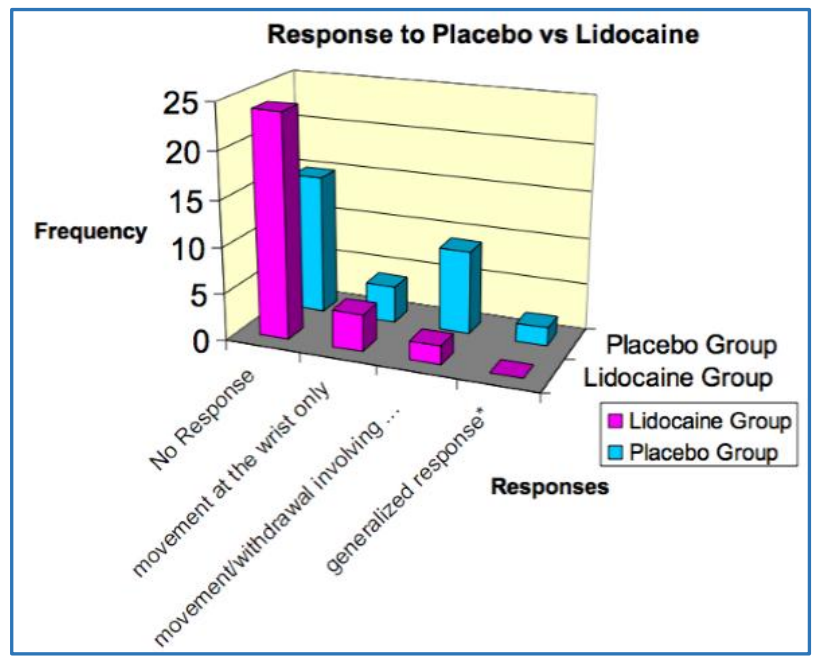

Response to Placebo vs. Lidocaine

*Withdrawal or movement in more than one extremity, cough or breath-holding.

**As per Shevchenko ${ }^{3}$

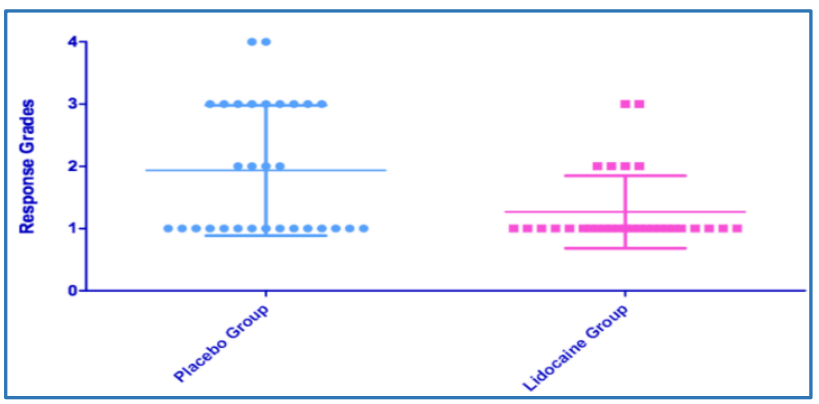

Graph 1: Pattern of Responses

None of the patients showed allergic reactions after injection of rocuronium or the pretreatment. No erythema or venous sequelae were observed in any patient during the 24hour follow-up and none remembered any pain or discomfort at the time of induction of anaesthesia. No other complications attributable to the drugs were noted. No patient complained of any residual pain.

\section{DISCUSSION}

There have been several reports of spontaneous movements after injection of intravenous rocuronium. Table 1 shows the incidence reported in different studies. Even after induction of anaesthesia with propofol or thiopental sodium, rocuronium causes hand or limb withdrawal or generalised movements suggesting the presence of intense nociception even under anaesthesia. Of interest is the observation that the brisk flexion of the elbow and wrist noted in patients after induction of anaesthesia was similar in nature and duration to that observed in awake patients. It is accepted that such spontaneous withdrawal movements under anaesthesia are due to pain on injection (Yvan A. Ruetsch, Alain Borgeat16). These withdrawal movements may cause dislocation or displacement of the IV catheter, causing difficulty in administrating additional drugs. In addition, Lui and Colleagues ${ }^{17}$ reported on a child who developed pulmonary aspiration secondary to gastric regurgitation after generalised spontaneous movements during rocuronium injection. Similarly, Morishima T, Sobue K and Arima $\mathrm{H}$ et al reported profound injection pain due to propofol injection triggering myocardial ischaemia in a patient with a suspected pheochromocytoma. ${ }^{18}$

\begin{tabular}{|c|c|}
\hline Reference No. & Incidence Reported \\
\hline 2 & $80 \%$ \\
\hline 3 & $84 \%$ \\
\hline 4 & $94 \%$ \\
\hline 5 & $82 \%$ \\
\hline 6 & $70 \%$ \\
\hline 7 & $57 \%$ \\
\hline 8 & $85 \%$ \\
\hline 9 & $62.5 \%$ \\
\hline 10 & $78 \%$ \\
\hline 11 & $90 \%$ \\
\hline 12 & $81 \%$ \\
\hline 13 & $66 \%$ \\
\hline 14 & $80 \%$ \\
\hline 15 & $77 \%$ \\
\hline 20 & $93 \%$ \\
\hline 21 & $95 \%$ \\
\hline 22 & $89.5 \%$ \\
\hline 23 & $87 \%$ \\
\hline Table 2: Incidence of Pain/Withdrawal Movement \\
Reported in Various Studies after Injection of \\
\multicolumn{2}{|c|}{ Rocuronium } \\
\hline \multicolumn{2}{|c|}{} \\
\hline
\end{tabular}

Attenuation of the pain caused by rocuronium injection could make it less distressing for the patient to receive and improve the quality of induction and acceptability of this otherwise useful agent.

Rocuronium has been injected faster or more slowly ${ }^{19}$ with or without a tourniquet, diluted or not. ${ }^{14}$ Local anaesthetics, opioids, ketamine, ondansetron, dexmedetomidine and other chemical substances have been given as pretreatment.

In adult patients, Cheong and Wong 15 found that lidocaine $30 \mathrm{mg}$ was more effective than lidocaine $10 \mathrm{mg}$ for the reduction of the incidence and severity of pain from injection of rocuronium. They suggested that higher doses (Such as 50 $\mathrm{mg}$ might completely abolish rocuronium injection pain. In this study we used the higher dose of lidocaine $(1 \mathrm{mg} / \mathrm{kg})$, which also prevents tachycardia and hypertension associated with tracheal intubation in several studies. Lidocaine is also a commonly used drug during induction and intubation. The application of venous tourniquet is useful for drugs with local anaesthetic properties such as lidocaine, ondansetron or tramadol.11 With the aim of keeping lidocaine within the vein, rocuronium was injected with manual occlusion. The lidocaine-manual occlusion (Similar to Bier's Block) method is undeniably effective and simple to perform, ${ }^{20}$ which we have chosen in this study.

It was also the most effective analgesic method in a systematic review 20 on methodologies to prevent the injection pain of propofol. Further studies would be required to find the optimal timing and duration for the occlusion technique.

The effect of lidocaine was more likely the result of local anaesthetic effect at the site of injection. In our study rocuronium was injected $15 \mathrm{~s}$ after lidocaine and a tourniquet was applied to the arm from the time of injection of lidocaine until rocuronium was injected. Therefore, a limited amount of the lidocaine injected reached the systemic circulation. 
When rocuronium is injected subsequently, lidocaine may be masked by a local anaesthetic effect on the vessel and prevent direct contact between rocuronium and the vessel, which leads to buffering with flowing blood.

As an induction agent, we used thiopental instead of propofol because compared with thiopental, pain on injection occurs significantly more commonly with propofol. Also thiopental can reduce the incidence of withdrawal movements on injection of rocuronium. ${ }^{21}$

Klement and Arndt 22 showed that injection of acidic solutions causes pain. The authors noted that after injection of acidic solutions, perivenous oedema developed immediately. In our study, we did not see such side effects. Because rocuronium bromide is formulated with sodium acetate, sodium chloride or acetic acid to produce a solution of $\mathrm{pH} 4$, Lockey and Coleman ${ }^{23}$ postulated that the low $\mathrm{pH}$ is a possible cause of pain. However, Borgeat and Kwiatkowski² speculated that local release of mediators might be implicated because of the short duration of the pain and the marked decrease or absence of pain during a subsequent second administration. Peripheral veins are innervated with polymodal nociceptors, which mediate the response to the injection of certain anaesthetics that cause pain. Blunk et $\mathrm{al}^{24}$ concluded that the algogenic effect of aminosteroidal neuromuscular-blocking drugs could be attributed to a direct activation of Cnociceptors.

In our study, the patient's demographic characteristics are comparable between the placebo and lidocaine groups. Lidocaine has reduced the severity of movements as depicted in graphs. The number of patients who exhibited generalised movement (response 4) with rocuronium injection was significantly lower: $0(100 \%)$ for the lidocaine group patients as compared to $2(6 \%)$ for the placebo group. The generalised response seen in both the patients of the placebo group was movement in more than one extremity. No cough or breath holding was noted in any of the patients.

In our study patients $>18$ years of age were enrolled, therefore paediatric patients were excluded.

In our study however lidocaine-occlusion technique did not completely abolish withdrawal movements. An experimental intervention that does not completely prevent pain may alleviate most symptoms. Such an intervention may of course be very useful. 20

Injecting lidocaine before rocuronium will prolong the time between the induction of anaesthesia and the administration of neuromuscular blockade, which is not desirable in situations in which rapid control of the airway is required. In addition the technique we used (manual occlusion) requires additional personnel to be effectively performed. Mixing lidocaine with rocuronium may alleviate this problem, but there are no data regarding the chemical compatibility of these drugs. Pretreatment with narcotic analgesics in whom it is not contraindicated, may also reduce the incidence of discomfort.

Pain on injection of rocuronium is significant and perhaps other clinical strategies could be developed to prevent it. Rocuronium is an invaluable addition to our practice allowing more rapid tracheal intubation.

The purpose of this study was to evaluate strategies to reduce the pain associated with the administration of rocuronium.
Rocuronium has been evaluated previously as a precurarisation agent; it demonstrates superior effectiveness compared with d-tubocurarine, vecuronium, atracurium and mivacurium in preventing fasciculations and postsuccinylcholine myalgias. ${ }^{25}$ The intense pain produced by rocuronium in patients has restricted its use as a precurarisation agent. The administration of lidocaine $1 \mathrm{mg} / \mathrm{kg}$ with occlusion technique prior to a precurarisation dose of rocuronium could reduce this problem as suggested by our study.

\section{CONCLUSION}

This study demonstrates that the IV injection of rocuronium after IV pentothal produces significant limb withdrawal or generalised movement in most adult patients. This reaction can be decreased in incidence and severity by the prior administration of $1 \%$ lidocaine, $1 \mathrm{mg} / \mathrm{kg}$ with the manual occlusion technique maintained for 15 seconds before the injection of rocuronium.

\section{REFERENCES}

1. Dalgleish DJ. Drugs which cause pain on intravenous injection. Anaesthesia 2000;55(8):828-9.

2. Borgeat A, Kwiatkowski D. Spontaneous movements associated with rocuronium: is pain on injection the cause? Br J Anaesth 1997;79(3):382-3.

3. Shevchenko Y, Jocson JC, McRae VA, et al. The use of lidocaine for preventing the withdrawal associated with the injection of rocuronium in children and adolescents. Anesth Analg 1999;88(4):746-8.

4. Kim JY, Kim JY, Kim YB, et al. Pretreatment with remifentanil to prevent withdrawal after rocuronium in children. Br J Anaesth 2007;98(1):120-3.

5. Kim KS, Kim YS, Jeon WJ, et al. Prevention of withdrawal associated with the injection of rocuronium in adults and children. Journal of Clinical Anesthesia 2006;18(5):334-8.

6. Choi BI, Choi SH, Yang-Sik S, et al. Remifentanil prevents withdrawal movements caused by intravenous injection of rocuronium. Yonsei Med J 2008;49(2):211-6.

7. Ahmad N, Choy YC, Aris EA, et al. Preventing the withdrawal response associated with rocuronium injection: a comparison of fentanyl with lidocaine. Anesth Analg 2005;100(4):987-90.

8. Han DW, Koo BN, Choi SH, et al. Neutralized rocuronium (pH 7.4) before administration prevents injection pain in awake patients: a randomized prospective trial. Journal of Clinical Anesthesia 2007;19(6):418-423.

9. Yavascaoglu B, Kaya FN, Ozcan B. Esmolol pretreatment reduces the frequency and severity of pain on injection of rocuronium. Journal of Clinical Anesthesia 2007;19(6):413-417.

10. Mahajan R, Batra YK, Kumar S. Pain on injection of rocuronium: influence of ketamine pretreatment. Can J Anesth 2005;52(1):111.

11. Memis D, Turan A, Karamanhoglu B, et al. The prevention of pain from injection of rocuronium by ondansetron, lidocaine, tramadol, and fentanyl. Anesth Analg 2002;94(6):1517-20.

12. Ertugrul F. A Comparison of the efficacies of different pretreatment drugs in resolving the injection pain of rocuronium. The Journal of International Medical Research 2006;34(6):665-70. 
13. Chiarella AB, Jolly DT, Huston CM, et al. Comparison of four strategies to reduce the pain associated with intravenous administration of rocuronium. Br J Anaesth 2003;90(3):377-9.

14. Tuncali B, Karci A, Tuncali BE, et al. Dilution of rocuronium to $0.5 \mathrm{Mg} / \mathrm{Ml}$ with $0.9 \% \mathrm{NaCl}$ eliminates the pain during intravenous injection in awake patients. Anesth Analg 2004;99(3):740-3.

15. Cheong KF, Wong WH. Pain on injection of rocuronium: influence of two doses of lidocaine pretreatment. Br J Anaesth 2000;84(1):106-7.

16. Ruetsch YA, Borgeat A. Withdrawal movements associated with the injection of rocuronium. Anesth Analg 2000;90(1):227-8.

17. Lui JT, Huang SJ, Yang CY, et al. Rocuronium-induced generalized spontaneous movements cause pulmonary aspiration. Chang Gung Med J 2002;25(9):617-20.

18. Morishima T, Sobue K, Arima H, et al. Profound pain due to propofol injection triggered myocardial ischemia in a patient with a suspected pheochromocytoma. Anesth Analg 2003;96(2):631.

19. Baek SH, Woo CM, Lee HJ, et al. Rocuronium-induced withdrawal movements associated with different rocuronium injection method. Paediatr Anaesth 2008; 18(6):515-9.
20. Picard P, Tramer MR. Prevention of pain on injection with propofol: a quantitative systematic review. Anesth Analg 2000;90(4):963-9.

21. Jong-Taek P, Jae-Chan C, Young-Soo Y, et al. The Effect of pretreatment with thiopental on reducing pain induced by rocuronium injection. Yonsei Med J 2005;46(6):765-8.

22. Klement W, Arndt JO. Pain on i.v. injection of some anaesthetic agents is evoked by the unphysiological osmolality or $\mathrm{pH}$ of their formulations. Br J Anaesth 1991;66(2):189-95.

23. Lockey D, Coleman P. Pain during injection of rocuronium bromide. Anaesthesia 1995;50(5): 474.

24. Blunk JA, Seifert F, Schmelz M, et al. Injection pain of rocuronium and vecuronium is evoked by direct activation of nociceptive nerve endings. Eur J Anaesthesiol 2003;20(3):245-53.

25. Martin R, Carrier J, Pirlet M, et al. Rocuronium is the best nondepolarizing relaxant to prevent succinylcholine fasciculations and myalgia. Can J Anaesth 1998; 45(6): 521-5. 